\title{
Evaluation of clinical and radiological outcomes of mineral trioxide aggregate and calcium hydroxide as indirect pulp capping agents in the treatment of deep carious lesion of permanent teeth
}

\author{
Rafeza Sultana, Mozammal Hossain and Md. Shamsul Alam
}

\begin{abstract}
Article Info
Department of Conservative Dentistry and Endodontics, Faculty of Dentistry, Bangabandhu Sheikh Mujib Medical University, Shahbag, Dhaka, Bangladesh

For Correspondence:

Rafeza Sultana

rafezasultana@gmail.com

Received:

Accepted:

Available Online:

20 August 2016

24 August 2016



5 September 2016

ISSN: 2224-7750 (Online)

2074-2908 (Print)

DOI: $10.3329 /$ bsmmuj.v9i3.29462

Cite this article:

Sultana R, Hossain M, Alam MS. Evaluation of clinical and radiological outcomes of mineral trioxide aggregate and calcium hydroxide as indirect pulp capping agents in the treatment of deep carious lesion of permanent teeth. Bangabandhu Sheikh Mujib Med Univ J. 2016; 9: 140-145.

Available at:

www.banglajol.info

A Journal of Bangabandhu Sheikh Mujib Medical University, Dhaka, Bangladesh

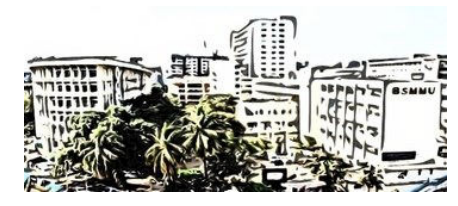

\section{Abstract}

\section{Introduction}

Concepts and treatment principles of deep carious lesions are an area of debate and constant change because the traditional concept of complete caries removal in very deep preparation has been challenged. Complete carious dentin removal may not be a prerequisite to arrest caries progression. It is well known that bacteria in the dentin cause pulpal inflammation and considered as a beneficial for pulp regeneration. 1 Therefore, an important priority in the treatment of deep carious lesion is to preserve pulp vitality.2 However after pulp exposure, such as conservative treatment is questionable and unpredictable. In addition, if pulp has become infected and exposed during caries removal, the successful outcome will be substantially reduced.2 Therefore, indirect pulp treatment in the form of one step or two step procedures has been suggested by some of the previous studies.3-5 In this technique, the removal of infected dentin leaving a thin layer of deeper affected dentin while complete carious lesion removal would result in pulp exposure. A period of 6 to 8 weeks time usually needs to produce adequate remineralization of the cavity floor as well as maintenance of a patent seal against microleakage by temporary and final restoration. 6

The search for the ideal vital pulp therapy
\end{abstract}

The maintenance of pulp vitality and conduction of reparative dentin can be possible by indirect pulp capping with mineral trioxide aggregate (MTA) and calcium hydroxide as pulp capping agents. The objective of the study is to assess the clinical and radiological outcomes of MTA and calcium hydroxide as indirect pulp capping agents in deep carious lesions of permanent teeth. The present study included 50 permanent teeth having deep carious lesions with reversible pulp status were selected and then randomly divided into two groups of 25 teeth in a group. Standard indirect pulp capping procedures were followed. Patients were recalled at 3, 6 and 12 months interval to assess postoperative pain, the vitality of the pulp and formation of reparative dentin. In all observation periods, MTA showed more capable of reducing pain and maintain pulp vitality which was statistically significant than that of calcium hydroxide. At 12 months observation period, 24 teeth $(96 \%)$ of MTA and 19 teeth $(76 \%)$ of calcium hydroxide showed reparative dentin formation. It can be concluded that MTA is more effective than that of calcium hydroxide.

material has led researchers to investigate many different materials. These include calcium hydroxide compound, zinc oxide, calcium phosphate, zinc phosphate and polycarboxylate cement, calcium tetracycline chelate, antibiotic and growth factor combination, calcium phosphate ceramics, emdogain, bioglass, cyanoacrylate, hydrophilic resins, hydroxyapatite, resinmodified glass ionomer and mineral trioxide aggregate (MTA).7 Portland cement is an effective and alternative to MTA. $\underline{8}$

Calcium hydroxide has been used as a pulp capping agent because it allows the formation of reparative dentin through cellular differentiation, extracellular matrix formation, and subsequent mineralization.., 10 Furthermore, it protects the pulp against thermoelectrical stimuli as well as antimicrobial action.11 However, long-term clinical studies have shown that failure rates of this material increase with time due to it does not provide close adaptation to dentin, gradual degradation, does not promote consistent odontoblast differentiation and has been shown to be cytotoxic in cell culture; tunnel defect in newly form dentin bridges may provide a pathway for the penetration of microorganisms to activate circulating immune cell, induce pulpal irritation and produce subsequent dystrophic calcification. $\underline{\mathbf{1 2 - 1 4}}$

As an alternative to calcium hydroxide, MTA, 
which contain a mixture of tricalcium silicate, tricalcium silicate, tricalcium aluminate, tetracalcium alluminoferite, calcium sulfate dehydrate and bismuth oxide for radio-opacity. $\underline{15}$ It is available in a fine hydrophilic powder in a sachet and mixed with distilled water (power: water: 3:1) on a mixing pad or a glass slab using a plastic or metal spatula and the setting time is about 2 hours and $45 \min .15-17$ Many studies have indicated that MTA develops minimal or no cytotoxic effects, reduce microleakage by synthesis mineralized dentin, induce secretion of reparative dentin formation as well as pulp healing due to its alkaline $\mathrm{pH} . \underline{16}$ Furthermore, it is a potent inhibitor of bacterial endotoxin and slowly release of calcium ions may give clinically better results than other materials.7,16 Moreover, it has no reaction with other dental materials and any restorative material can be used over MTA pulp capping. $\underline{18}$

Therefore, it can be considered that MTA could be an alternative pulp capping agent to calcium hydroxide. However, few clinical studies have been performed regarding this matter. Therefore, the clinical and radiological outcomes need to be verified before making any conclusion. So, the purpose of the study was to compare its clinical and radiological outcomes of MTA with that of calcium hydroxide in permanent teeth.

\section{Materials and Methods}

The prospective comparative study was conducted in the Department of Conservative Dentistry and Endodontics, Faculty of Dentistry, BSMMU over a period of 18 months from April 2014 to October 2015. The proposed study protocol was approved by the Ethical Review Committee, BSMMU.

Fifty permanent teeth from 43 individual (age 16-30 years) patients were selected. The patient who met the inclusion criteria such as permanent teeth having a deep carious lesion which was closer to but not involving the pulp, having reversible pulp status based on the clinical sign, symptom, and radiograph and could be restorable, were selected. The clinical and radiological evaluations were done prior to entering into the study.

To minimize the allocation bias, the 50 teeth were randomly assigned into two groups. In Group A and $B$, indirect pulp capping was done by calcium hydroxide and MTA, respectively. Verbal data was collected after a written informed consent taken from every patient/ patient's legal guardian (for $<18$ years). The pulp vitality test, palpation and percussion tests were performed in standard procedure and radiograph was examined to assess the pulpal health for each patient. Patient's symptoms, clinical signs and a detailed medical and dental history were recorded in a prefixed data collection sheet and the radiograph was taken for each case. The radiographs were examined by the same evaluator and recorded in the data collection sheet. Proper counseling of the patient and/or patient's parent was done about the treatment procedure, its benefit and cost. Eradication of plaque and calculus by mouth scaling were performed.

Hand gloves, face masks were ensured in every case in an aseptic manner. Disinfection of the operation field and proper sterilization were ensured. Local anesthesia was administered and isolation of teeth was maintained with a rubber dam. Firstly, the carious lesion was removed by using diamond round bur at high speed with sufficient cooling arrangement. Then judicial removal of soft, deep carious dentin by using low-speed round steel bar. Infected dentin at the dentino-enamel junction was removed with a spoon excavator and remaining caries was removed by using low-speed round carbide burs compatible with the size of the cavity carefully to avoid pulp penetration.

Calcium hydroxide powder (Deepti Dental Product, India) was mixed with normal saline to a thick consistency. The paste was carefully placed by calcium hydroxide applicator into the base of the prepared cavity up to 0.5 to $1 \mathrm{~mm}$ thickness. Then the base of the cavity was filled with Fuji-IX glass ionomer cement and restored by composite restoration (giomer) to replace enamel. Occlusion was checked for any high spots. Then postoperative radiograph was taken as baseline radiograph. MTA (Proroot, Dentsply, Tulsa Dental, USA) powder was mixed with sterile water in a 3:1 ratio, according to the manufacturer recommendation and placed on the operative site with amalgam carrier up to 2-3 millimeter thickness and applied by light pressure with moist cotton pellets. A damp cotton pellet was placed over MTA and then sealed with a temporary cement to allow for a final set of the MTA. The patient was recalled at 2 nd visit within 12 to 48 hours and following the removal of the temporary cement and cotton, MTA was examined to ensure that it set hard and the tooth was restored with composite restoration (Giomer) to replace enamel. Occlusion was checked for any high spot. Then postoperative radiograph was taken as baseline radiograph. Patients were advised to maintain oral hygiene instructions and avoid taking any analgesics in the case of mild pain during follow-up period. The patient was recalled for clinical and radiological evaluation at 3,6 and 12 months interval.

The clinical evaluation was done for each patient by the designated investigators at every follow-up visit by the presence or absence of signs and symptoms. Blind to the treatment record, two evaluators have assessed the clinical findings. The following clinical assessments were performed: Pain assessment was 
performed according to VAS (Visual Analogue Scale) system. According to this method, VAS of a $10 \mathrm{~cm}$ long horizontal line with points labeled as 0 10 to describe the pain, no pain (0), mild pain (1-3), moderate pain (4-6) and severe pain (7-10). In data collection, sheet pain was recorded as, no pain (0), mild pain (1), moderate pain (2) and severe pain (3).

Pulp vitality was assessed by vitality test. Thermal test, both cold and heat test was done. Cold test: Isolation of the teeth was done with a cotton roll. The cold test was performed with ice stick wrapped with a gouge and applied on the adjacent, contralateral and opposite teeth of the experimental tooth to record the normal response of individual. Then ice stick wrapped with gauge was applied on the experimental tooth surface and patient's response was noted.

The heat test was performed following coated the teeth with vaseline to prevent the adhesion of heated gutta parcha to teeth surface. Then the normal response was recorded of individual by application of heated gutta parcha on the adjacent, contralateral and opposite teeth of the experimental tooth. After that, the heated gutta parcha was applied on the experimental tooth surface and the

\section{Table I}

Comparison of pain level (VAS) between the two groups

\begin{tabular}{|lrrr|}
\hline $\begin{array}{l}\text { Pain level (VAS) evalua- } \\
\text { tion period }\end{array}$ & $\begin{array}{r}\text { Calcium } \\
\text { hydroxide } \\
(\mathrm{n}=25)\end{array}$ & $\begin{array}{r}\text { MAT } \\
(\mathrm{n}=25)\end{array}$ & p value \\
\hline Baseline & 0 & 0 & $0.684^{\mathrm{ns}}$ \\
No pain & 22 & 21 & \\
Mild pain & 3 & 4 & \\
Moderate pain & 0 & 0 & 0.034 \\
Severe pain & & & \\
After 3 months & 17 & 23 & \\
No pain & 8 & 2 & 0.042 \\
Mild pain & 0 & 0 & \\
Moderate pain & 0 & 0 & \\
Severe pain & & & \\
After 6 months & 19 & 24 & \\
No pain & 6 & 1 & \\
Mild pain & 0 & 0.042 \\
Moderate pain & 0 & 0 & \\
Severe pain & 0 & 0 & \\
After 12 months & 19 & 0 & \\
No pain & 0 & 0 & \\
Mild pain & 0 & 0 & \\
Moderate pain & 0 & 0 & \\
Severe pain & 0 & 0 & \\
\hline
\end{tabular}

response was noted. In data collection sheet the response was recorded as, positive (normal) response (1), exaggerated brief $(<15 \mathrm{sec}$, reversible pulp status) (2), exaggerated prolong (>15 sec, irreversible pulp status) and negative response (nonvital) (0).

Reparative dentin formation was assessed by means of intraoral periapical radiograph (IOAP). Same $x$ ray machine (BLUEX, IntraOs $7070 \mathrm{KVP} 7 \mathrm{~mA}$, FONA SRL, Italy), same position, same technique and same technician were used for every case. Reparative dentin formation was observed (present/absent) from the radiograph at 3, 6 and 12 months interval. In data collection sheet it was recorded as, present (1) and absent (2).

The data were analyzed using computer-based statistical software, SPSS 20.00 version (SPSS Inc. USA). Significant of difference Chi-square test was done to compare between two groups and 95\% confidence interval ( $p$ value $<0.05$ ) was followed by testing level of significance.

\section{Results}

The results of the assessment of pain by VAS were showed in Table I. It was found that at the baseline, 22 of 25 teeth in calcium hydroxide group and 21 of 25 teeth in MTA had mild pain. The remaining 3 calcium hydroxide and 4 MTA treated teeth revealed moderate pain. However, the pain was reduced during follow-up period in both groups. At 3 months, 8 calcium hydroxide and only 2 MTA treated teeth had mild pain. The differences between two groups were statistically significant $(\mathrm{p}<0.05)$. At 6 and 12 months follow-up period, in 6 calcium hydroxide treated teeth, and 1 MTA treated tooth had mild pain. The remaining cases revealed no pain at these observation periods. Furthermore, the differences between MTA and calcium hydroxide treated groups were statistically significant $(\mathrm{p}<0.05)$.

The results of the assessment of pulp vitality (cold and heat test) were showed in Table II. It was observed that at the baseline, all teeth treated either by calcium hydroxide or MTA had exaggerated brief (pain linger less than $15 \mathrm{sec}$ ) respond to the cold test.

The results of the assessment of conduction of reparative dentin were showed in Table III. It was found that at the baseline, none of calcium hydroxide and MTA-treated teeth revealed any sign of reparative dentin formation (Figure 1). However, at 3 months observation period, hard tissue-like structure (reparative dentin) was recognized beneath the restoration in 17 calcium hydroxide- and 23 MTA-treated teeth. Furthermore, at 6 and 12 months observation period except in 6 
Table II

Comparison of pulp vitality status regarding cold and heat test between the two groups

\begin{tabular}{|c|c|c|c|}
\hline $\begin{array}{l}\text { Pulp status evaluation } \\
\text { period }\end{array}$ & $\begin{array}{l}\text { Calcium } \\
\text { hydroxide } \\
(\mathrm{n}=25)\end{array}$ & $\begin{array}{c}\text { MAT } \\
(\mathrm{n}=25)\end{array}$ & $\mathrm{p}$ value \\
\hline \multicolumn{4}{|l|}{ Baseline } \\
\hline Normal response & 0 & 0 & \multirow[t]{4}{*}{ - } \\
\hline Exaggerated brief & 25 & 25 & \\
\hline Exaggerated prolong & 0 & 0 & \\
\hline Negative & 0 & 0 & \\
\hline \multicolumn{4}{|l|}{ After 3 months } \\
\hline Normal response & 17 & 23 & \multirow[t]{4}{*}{0.034} \\
\hline Exaggerated brief & 8 & 2 & \\
\hline Exaggerated prolong & 0 & 0 & \\
\hline Negative & 0 & 0 & \\
\hline \multicolumn{4}{|l|}{ After 6 months } \\
\hline Normal response & 19 & 24 & \multirow[t]{4}{*}{0.042} \\
\hline Exaggerated brief & 0 & 0 & \\
\hline Exaggerated prolong & 0 & 0 & \\
\hline Negative & 6 & 1 & \\
\hline \multicolumn{4}{|l|}{ After 12 months } \\
\hline Normal response & 19 & 24 & \multirow[t]{4}{*}{0.042} \\
\hline Exaggerated brief & 0 & 0 & \\
\hline Exaggerated prolong & 0 & 0 & \\
\hline Negative & 6 & 1 & \\
\hline
\end{tabular}

\section{Table III}

Comparison of reparative dentin formation between the two groups

\begin{tabular}{lrrr|}
$\begin{array}{l}\text { Reparative dentin for- } \\
\text { mation status evaluation } \\
\text { period }\end{array}$ & $\begin{array}{r}\text { Calcium } \\
\text { hydroxide } \\
(\mathrm{n}=25)\end{array}$ & $\begin{array}{c}\text { MAT } \\
(\mathrm{n}=25)\end{array}$ & p value \\
\hline $\begin{array}{l}\text { Baseline } \\
\text { Present }\end{array}$ & 0 & 0 & - \\
$\quad$ Absent & 25 & 25 & \\
After 3 months & 17 & & 0.034 \\
Present & 8 & 23 & \\
Absent & & 2 & 0.042 \\
After 6 months & 19 & 24 & \\
Present & 6 & 1 & 0.042 \\
Absent & & & \\
After 12 months & 19 & 24 & \\
Present & 6 & 1 & \\
Absent & & & \\
\hline
\end{tabular}

calcium hydroxide and 1 MTA treated teeth, all cases showed evident of reparative dentin formation. The differences between two groups were statistically significant $(\mathrm{p}<0.05)$.

\section{Discussion}

In this study, postoperative pain, pulp vitality and conduction of reparative dentin by MTA and calcium hydroxide as indirect pulp capping agents were verified in vivo. The assessment of pain and pulp vitality at 12 months following completion of treatment revealed that there was no pain in 19 out of $25(76 \%)$ of calcium hydroxide and 24 of $25(96 \%)$ of MTA-treated teeth which were positively (normal) respond to pulp vitality test. In respect to pain and pulp vitality test, at 3 months observation period, the clinical success rate was $92 \%$ with MTA and $68 \%$ with calcium hydroxide. At 6 and 12 months observation period, the clinical success rate was $96 \%$ with MTA. On the other hand, the clinical success rate was $76 \%$ with calcium hydroxide. The differences between two groups were statistically significant. It indicated that MTA was more effective in reducing pain and maintain the pulp vitality than that of calcium hydroxide as indirect pulp capping agent.

However, $6(24 \%)$ calcium hydroxide and $1(8 \%)$ MTA treated teeth had mild pain along with no respond to pulp vitality test. Almost similar results were reported by Benoist et al. $\underline{19}$ that there were 4 failures in calcium hydroxide treated teeth and 1 additional failure was found in MTA treated tooth. They indicated that failure was due to loss of the restoration. Although no restoration was lost in the present study but it can be said that failure (did not respond to pulp vitality test) in the present study may be due to microleakage of restoration interface followed by necrosis of the pulp. A further observation is needed to confirm whether these teeth required any treatment or not.

The results of pain and pulp vitality found in the present study were also corresponded to Benoist et al. 19 who indicated that at 3 months, the clinical success rate of MTA and calcium hydroxide were 93 and $73 \%$, respectively. At 6 months, the success rate was $89.6 \%$ with MTA and remained steady at $73 \%$ with calcium hydroxide. Moreover, 93\% success rate at 3 months with MTA was obtained by Bogen et al. 7

The reason for mild pain occurred following treatment with either calcium hydroxide and MTA group was not clearly understood from the present study. It might be possible that the pulp in these teeth was already inflamed prior to treatment and initial postoperative pain was likely to be a sign of exacerbation of this inflammation the following 


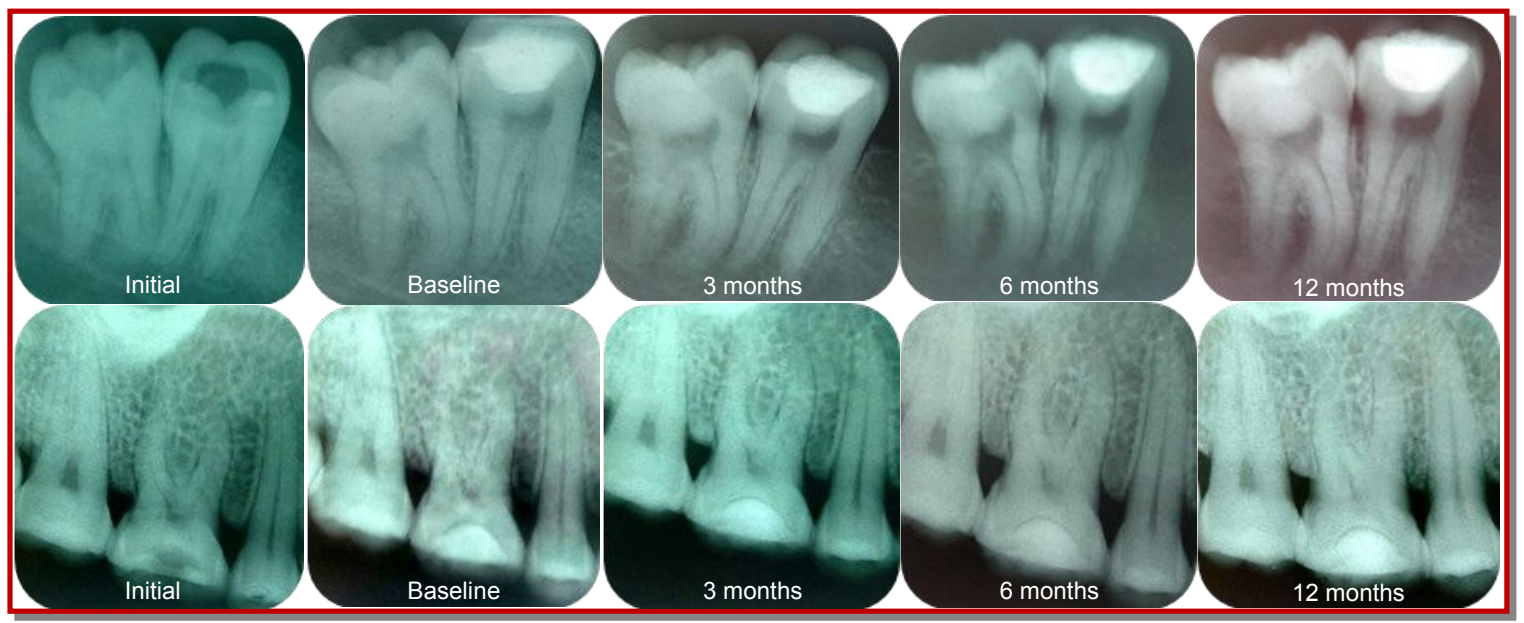

Figure 1: Representative radiological photographs of reparative dentin formation by MTA (upper row photographs) and calcium hydroxide (Lower row photographs)

treatment. This is supported by a previous study that stimulation of affected dentin produces pain or it may occur as a result of pulp undergoing necrosis followed by apical periodontitis.르 Pain may also occur due to the composition of the materials too.21 Further additional researches are needed to investigate the cause of pain.

Regarding reparative dentin formation, the results of the study revealed that at 3 months, $17(68 \%)$ calcium hydroxide and 23 (92\%) MTA treated teeth showed the reparative dentin formation radiologically. The remaining $8(32 \%)$ calcium hydroxide and $2(8 \%)$ MTA did not clearly evident the reparative dentin formation. The reason might be due to having the radiographic beam not always perfectly perpendicular to the axis of the tooth and the exposure site at the same time. $\underline{22}$ Furthermore, the reparative dentin formation with MTA is faster with good structural integrity and more complete than with calcium hydroxide. $\underline{23}$ The conduction of reparative dentin can also be identified in histological studies,22 which was not performed in the present study.

At 6 and 12 months observation period, it was found that $19(76 \%)$ calcium hydroxide and 24 (96\%) MTA treated teeth showed reparative dentin formation. It can be considered that the success of pulp capping agent depends on the thickness of the newly formed dentin. As the thickness of newly formed dentin was not evaluated in the present study, but the previous study reported that the thickness of reparative dentin in calcium hydroxide and MTA were different in first 3 months, while there were no differences between two materials with an increase of observation period. $\underline{19}$ Therefore, additional histological investigations are needed to support these findings.

The mechanism of hard tissue formation by MTA or calcium hydroxide is also not clarified in the present study. Moretton et al. $\underline{24}$ suggested that MTA is osteoconductive in indirect pulp capping therapy that stimulates the production of mineralized tissue in areas where this tissue is normally present, indirectly as a part of stereotypic wound healing mechanism. The formation of dentin adjacent to the MTA occurs due to its sealing ability, which prevents microleakage. It is also biocompatible and has the capacity to stimulate cytokine release by the hard tissue forming cells. On the other hand, calcium hydroxide promotes the dentin repair due to its high $\mathrm{pH}$ which directly induces reparative hard tissue formation in the dental pulp. $\underline{25}$ However, based on the present and together with the previous studies, it can be considered that MTA is more effective than calcium hydroxide as indirect pulp capping material.

\section{Conclusion}

Clinical outcomes and conduction of reparative dentin by MTA are more effective as indirect pulp capping agent than that of traditional calcium hydroxide. Additional histological investigations are needed to support and enrich these findings.

\section{References}

1. Gruythuysen RJ, Vanstip AJ, Wu MK. Long-term survival of indirect pulp treatment primary and permanent teeth with clinically diagnosed deep carious lesions. J Endod. 2010; 36: 1490-93.

2. Miyashita H, Worthington HV, Qualtrough A, Plasschaert A. Pulp management for caries in adults: Maintaining pulp vitality. Cochrane Database Syst Rev. 2007; 18: CD004484.

3. Dumsha T, Hovland E. Consideration and treatment of direct and indirect pulp capping. Dent Clin 
North Am. 1985; 29: 251-59.

4. Lakeshell E, ridell K, Cvek M, Mejare I. Pulp exposure after stepwise versus direct complete excavation of deep carious lesions in young posterior permanent teeth. Endo Dent Traumatol. 1996; 12: 192-96.

5. Maltz M, de Oliveira EF, Frontanella V, Bianchi R. A clinical, microbialogical, and radiological study of deep carious lesions after incomplete caries removal. Quintessence Int. 2002; 33: 151-59.

6. Jordan RE, Suzuki M. Conservative treatment of deep carious lesions. J Can Dent Asscc. 1971; 10: 134-39.

7. Bogen G, Chandler NP. Vital pulp therapy. In: Ingle's endodontics. Ingle JI. $6^{\text {th }}$ edn. Onterio, BC Decker Inc, 2008, pp 1110-30.

8. Nahar K, Bashar A, Hossain M, Moral A. Clinical and computed tomographic evaluation of portland cement pulpotomy in primary molar: A case report. Bangabandhu Sheikh Mujib Med Univ J. 2014; 7: 141-46.

9. Daurte MA, Mattins CS, Oliveira DE, Cardoso, Dimarchi AC. Calcium and hydroxide release from different pulp capping materials. Oral Surg Oral Med Oral Pathol Oral Radiol Endo. 2007; 104: 66-69.

10. Mizuno M, Banzai Y. Calcium ion release from calcium hydroxide stimulated fibronectin gene expression in dental pulp cells and the differentiation of dental pulp cells to mineralized tissue forming cells by fibronectin. J Int Endod. 2008; 41: 933-38.

11. Accorinte MI, Holland R, Reis A. Evaluation of MTA and $\mathrm{Ca}(\mathrm{OH})_{2}$ as pulp capping agents in human teeth. J Endod. 2008; 34: 1-6.

12. Olsson H, Petersson K, Rohlin M. Formation of hard tissue barrier after pulp capping in human. A systematic review. Int Endod J. 2006; 39: 429-42.

13. Auschill TM, Anweiler NB, Hellwig E, ZamaniAlaei A, Sculean A. Success rate of direct pulp capping with calcium hydroxide [in German]. Schweiz Monatsschr Zahnmed. 2003; 113: 946-52.

14. Barthel CR, Rosencranz B, Leuenberg A, Roulet JF. Pulp capping carious exposures, treatment outcome after 5 and 10 years: A retrospective study. J
Endod. 2000; 26: 525-28.

15. Camelleri J, Montesin FE, Brady K. The constitution of mineral trioxide aggregate. Dent Mater. 2005; 21: 297-303.

16. Roberts HW, Toth JM, Berzins DW, Charlton DG. Mineral trioxide aggregate material use in endodontic treatment. Dent Mater Rev. 2008; 24: 149-64.

17. Waiker MP, Diliberto A, Lee C. Effect of setting conditions on mineral trioxide aggregate flexural strength. J Endod. 2006; 32: 334-36.

18. Nandini S, Ballal S, Kandaswamy D. Influence of glass ionmer cement on the interface and setting reaction of mineral trioxide aggregate when used as a furcal repair material using laser Raman spectroscopic analysis. J Endod. 2006; 33: 167-72.

19. Benoist FL, Ndiaye FG, Kane AW, Benoist HM, Farge P. Evaluation of mineral trioxide aggregate (MTA) versus calcium hydroxide cement (Dycal) in the formationof a dentine bridge: A randomized controlled trial. J Int Dent. 2012; 62: 33-39.

20. Harald OH, Edward JS, Andre VR. Sterdevant's art \& science of operative dentistry. India, Elsevier, 2013.

21. Maroto M, Barberia E, Planells P, Ranly D, GarciaGodoy F. Current and potential pulp theraphies for primary and young permanent teeth. J Dent. 2000; 28: 53.

22. Najat F, Najla A, Khalid B, Abdullah AM. Clinical assessment of mineral trioxide aggregates (MTA) as direct pulp capping of young permanent teeth. J Clin Pediart Dent. 2006; 31: 72-76.

23. Holland GR, Trowbridge HO, Rafter M. Pro-tecting the pulp and preserving the apex. In: Endodontics: Principles and practice. Torabinejad M, Walton RE. $4^{\text {th }}$ edn. USA, Saunders Elsevier, 2002, pp 21-37.

24. Moretton TR, Brown Junior CE, Legan J, Kafrawy $\mathrm{AH}$. Tissue reaction after subcutaneous and intraosseous implantation of mineral trioxide aggregate and ethoxibenzoic acid cement. J Biom Mat Res. 2000; 52: 528-33.

25. Ranly DM, Garcia-Godoy F. Current and potential pulp therapies for primary and young permanent teeth. J Dent. 2000; 28: 153-61. 